\title{
DESPOSESIÓN, ARRAIGO, COALICIONES Y SUBJETIVACIÓN POLÍTICA DE POBLADORES PAMPEANOS Y BANQUINEROS DEL CHACO, ARGENTINA ${ }^{1}$
}

\section{DISPOSSESSION, ROOTING, COALITIONS AND POLITICAL SUBJECTIVATION ABOUT THE RURAL PAMPEAN PEOPLE AND BANQUINEROS FROM CHACO, ARGENTINA}

\author{
Joaquín Rotman* \\ María Amalia Miano** \\ Ana Inés Heras*
}

\begin{abstract}
RESUMEN
Se presenta un análisis de procesos socio-comunitarios rurales en las Provincias de Buenos Aires y Chaco, Argentina, relevados desde 1991 y 2015 — respectivamente-, con un enfoque etnográfico colaborativo. La metodología de análisis se construyó a partir de la combinación de la etnografía y la sociolingüística, así como al relacionar dichos enfoques con otras disciplinas (psicología social, sociología y filosofía política) se construyó un marco conceptual desde el que se interpretan los dos procesos mencionados. Los principales resultados refieren que, a través de este marco de trabajo, es posible identificar e interpretar acciones que configuran procesos de subjetivación política que de otra manera pasarían desapercibidas. Esas acciones refieren a la singularización, la creación de vincularidad y la disputa contra el arrasamiento.
\end{abstract}

$1 \quad$ Este artículo forma parte del Programa de Investigación "Aprender de y en Autogestión”, financiado por la Agencia Nacional de Promoción Científico Tecnológica (ANPCyT) (РICT 2015-0943) y radicado en el Laboratorio de Investigación en Ciencias Humanas (LICH-UNSAM-CONICET) y el Instituto para la Inclusión Social (INCLUIR).

* $\quad$ Facultad de Psicología, Universidad de Buenos Aires, Buenos Aires, Argentina.

Joaquin_rotman@hotmail.com

** Laboratorio de Investigación en Ciencias Humanas (LICH-UNSAM-CONICET) e Instituto para la Inclusión Social (INCLUIR), Buenos Aires, Argentina.

amiano@unsam.edu.ar

*** Laboratorio de Investigación en Ciencias Humanas (LICH-UNSAM-CONICET) e Instituto para la Inclusión Social (INCLUIR), Buenos Aires, Argentina.

aheras@unsam.edu.ar 
PALABRAS CLAVE: ARGENTINA * ACCIÓN COMUNITARIA * MEDIO RURAL * DERECHO DE AUTODETERMINACIÓN * DERECHO TERRITORIAL

\begin{abstract}
This paper presents and analyzes socio-communitarian rural processes in the Provinces of Buenos Aires and Chaco, Argentina, documented from 1991 and 2015 -respectivelythrough a collaborative ethnographys approach and using sociolinguistic methodologies. In order to build a theoretical framework, these disciplines are put in relationship to other areas of knowledge i.e., philosophy, social psychology and sociology. In doing so, it is possible to uncover and interpret actions that otherwise remain invisible, such as singular processes of subjectivation, the creation of coalitions and the struggle against the obliteration of life.
\end{abstract}

KEYWORDS: ARGENTINA * COMMUNITY ACTION * RURAL ENVIRONMENT * SELF-DETERMINATION * TERRITORIAL RIGHTS

\section{INTRODUCCIÓN}

En este artículo se presenta un análisis de acciones comunitarias en dos localidades rurales de las Provincias de Buenos Aires y del Chaco. Aunque pertenecen a geografías muy distintas en la Argentina, estos espacios presentan similitudes por el hecho de que ambas regiones han sido modificadas por procesos de acaparamiento de tierras afines al modelo extractivista presente en el agro argentino. También, en ambos espacios se han dado procesos de toma de decisiones llevadas adelante a través de acciones que transforman el contexto local a favor de lo que algunas coaliciones entre familias rurales $y$ otros agentes locales (maestros, activistas comunitarios, empleados y funcionarios) del INTA (Instituto Nacional de Tecnología Agropecuaria) y del Ministerio de Educación Provincial, denominan el "arraigo", es decir, su elección de vivir en el entorno rural.

Se sostiene que algunas de las acciones emprendidas en cada contexto singular no admiten fácilmente ser explicadas como acciones de clase social o como configuración de un sujeto político, aunque, según este análisis, son efectivamente procesos de subjetivación política (Tassin, 2012). Allí reside la fertilidad de la propuesta de análisis desde la perspectiva de la subjetivación política: es un marco para pensar cómo en la propia existencia cotidiana se produce la acción y el efecto de vivir políticamente. En este sentido, la decisión de seguir siendo habitantes rurales se configura en contextos donde la vulneración, la marginación y la violencia - que se produce en algunos casos explícitamente $y$ en otros de modo implícito- se entraman fuertemente. Se interpreta que cada acto referido al arraigo no es solo una expresión de deseo, sino, sobre todo, una acción desplegada para enfrentar un marco que pareciera no dejar salida alguna: el de la necropolítica.

Se apela al concepto de subjetivación política para referirse a este tipo de elecciones y las formas de llevarlas a cabo, ya que son acciones transformadoras en un sentido doble: quienes participan se tornan distintos a sí mismos, al mismo tiempo que modifican también el entorno. De esta forma, estos habitantes rurales intervienen en sus condiciones de vida, no como un sujeto colectivo creado ex profeso a estos efectos (por ejemplo, el campesinado), sino a través de un proceso de subjetivación política configurado por acciones constantes que producen efectos: se crean organizaciones (una escuela donde antes no había), se producen coaliciones (una alianza donde antes no existía, que inclusive luego puede desarmarse o reformularse) o se habitan tierras de otro modo (se ocupa, se habita colectivamente, se distribuye $y$ se mantiene una vida en la banquina). Tassin (2012) toma una postura crítica hacia otros autores, por ejemplo, Rancière, ya que sostiene que dicho autor asume finalmente una perspectiva explicativa que precisa de identificar un sujeto universal y universalizable. 
Así, para comprender las transformaciones que se producen, primero es necesario identificarlas, ya que no parecen poder percibirse desde las lecturas más corrientemente adoptadas. De acuerdo al marco de este texto, se propone entenderlas precisamente como acciones políticas puesto que desafían la soberanía y la política de la muerte, forma que tiene la última palabra sobre el control de los cuerpos (Mbembé, 2003).

Así, entonces, esta perspectiva se diferencia de tradiciones que recuperan la idea del campesinado como atrasado, pobre, subalterno, invisibilizado, viable-inviable, o bien, como revolucionario (Conti, 2017). Estas formas de comprender al campesinado se refieren a conceptualizaciones de autores $y$ autoras, líneas $y$ disciplinas diversas que se han ido ligando entre sí a lo largo de sus desarrollos. En principio, Marx (1852) se interesó por analizar el rol del campesinado de acuerdo a su potencialidad revolucionaria (o no), aspecto que sigue teniendo peso en la literatura de la Sociología rural contemporánea desde la perspectiva de personas autoras que se reconocen como marxistas (Amin, 2010). Asimismo, los estudios pioneros de Thomas y Znanieki (1918) ponen en consideración la marginación y pasividad política de la población rural.

Otra línea posterior es la de los llamados "Estudios Sociales Agrarios" que, desde la década del 60, ponen a debate fundamentalmente la persistencia o descomposición del campesinado como clase y las implicancias de procesos de reformas y contrarreformas agrarias (Cáceres, 2014). También otros estudios, propios de la Antropología y Sociología desde la década de los 90, hacen referencia a la homogeneidad o heterogeneidad de los actores rurales y a su persistencia por la capacidad de adaptabilidad sustentada en una condición multi-identitaria (Bengoa, 2003). Por último, se identifican estudios desde la Psicología, en particular desde la Psicología social latinoamericana centrados en identificar y analizar la posición campesina desde conceptos como "indolencia" o "indefensión aprendida" (Martín-Baró, 1986; Montero, 1994), o incluso, desde la "racionalidad del actor" (Landini, 2009).
Para presentar la elaboración conceptual, se han organizado la exposición en secciones como se describe a continuación. En primer lugar, se describen las conceptualizaciones forjadas desde la Psicología social ligadas al trabajo de Enrique Pichón-Rivière (1907-1977) a partir de la década de los 50 en Argentina $y$ se ponen en relación con nociones de otras disciplinas articuladas posteriormente por pensadores de distintas regiones (Latinoamérica, África y Europa): Silvia Rivera Cusicanqui (1949), Achille Mbembé (1957) y Etienne Tassin (1955-2018). Al tomar esta matriz analítica, en un segundo momento, se explica cómo se ha trabajado con pobladores rurales y se proponen interpretaciones que dan cuenta de acciones para defender la vida llevadas a cabo por coaliciones comunitarias de docentes, familias y otros actores locales que se ponen en tensión con lo que se identifica como "necropolítica" (Mbembé, 2003). De este modo, tal como se indicó al comienzo, la intención es presentar un análisis a partir de un encuadre conceptual que permita identificar fenómenos del ámbito rural que de otras maneras pasan desapercibidos o no se interpretan como procesos políticos.

\section{PSICOLOGÍA SOCIAL Y PROCESOS DE}

SUBJETIVACIÓN POLÍTICA: APORTES DE LA CONSTRUCCIÓN TEÓRICA DE PICHÓN-RIVIÈRE

En este apartado, se reconstruirán los modos en que Pichón-Rivière configuró algunos puntos centrales de su posición teórica, al señalar su interés en producir una teoría social que permitiera dilucidar la relación entre salud, aprendizaje, toma de decisiones, vida política y lo marginado, tomando como referencia su propio conocimiento sobre la vida rural. De allí su decisión de llamar "Psicología social" tanto a aquello desde dónde comprender al ser humano en sus complejas relaciones consigo mismo, con el entorno geográfico y con el contexto socio-histórico (Pichón-Rivière, 1969a), así también a una forma de intervenir en la transformación social. Este posicionamiento puede leerse en términos de la explicitación e implicancias de una dimensión política intrínseca de la existencia, al articular lo singular, lo colectivo y lo histórico-social. 
Pichón-Rivière nació en Suiza, pero emigró con su familia a la Argentina cuando tenía tres años. Vivió en su primera infancia en diversas localidades rurales en el Chaco argentino y luego en las Provincias de Corrientes y Santa Fe y, finalmente, en Buenos Aires. Por numerosas fuentes se sabe que fijó un temprano interés en cuanto a lenguas, prácticas de vida, trabajo y bagaje cultural en comunidades rurales (Fabris, 2014; Quiroga, 1985). Sus conocimientos sobre el mundo rural fueron luego retroalimentados desde sus estudios en medicina, psiquiatría, psicoanálisis y su incursión en otras disciplinas humanísticas —artes plásticas, la literatura y la música-. Por otra parte, cuando migró a ciudades grandes, se preocupó por conocer los considerados "bajos fondos" - enseñó francés a prostitutas y se vinculó también al mundo del boxeo-. Estas referencias permiten identificar una orientación socio-antropológica y político-filosófica, con enfoque psicológico y psicoanalítico, en donde se teorizaba desde lo considerado marginado. Por ejemplo, su perspectiva permitió diagnosticar que el tipo de trabajo que realizaban los varones en ámbitos rurales era sumamente exigente para sostener la institución familiar como se la interpretaba en la época, con lo que la itinerancia era lo natural $-y$ no el establecimiento permanente en una localidad o geografía - dada la continua emigración para buscar trabajos temporales de cosecha en otras provincias. De este modo, puso de relieve una serie de supuestos acerca de lo considerado "normal" a nivel social y cultural.

A su vez, este modo de ir construyendo su marco conceptual permite pensar sus desarrollos entramados a profundas implicancias político-filosóficas al construir teoría, cuyo eje más fuerte fue la elucidación del ser humano en situación. Desde mediados de la década de los 50 , Pichón-Rivière comienza a pensar el interjuego entre lo inconsciente y lo consciente anudado a lo vincular, excediendo lo intrapsíquico (Becerra, 2015). Distingue entonces que la patología mental en un sujeto es un emergente del grupo de referencia, sea este familiar, comunitario o social y, a partir de su conceptualización en psicología social, sostuvo fuertemente la ligazón entre enfermedad, grupo y estructura social. De este modo:

A partir de una visión integradora del "hombre en situación", y desde un enfoque interdisciplinario, no podemos referirnos al problema de la prevención sin tratar de ubicarlo en su contexto apropiado. La salud mental (...) no es para nosotros un valor absoluto y resulta evaluable en términos de comportamiento social. Este comportamiento, su operatividad o su deterioro, está íntimamente ligado a factores de orden socioeconómico y familiar, que intervienen o determinan, en forma positiva o negativa, una adaptación activa a la realidad, en la que el sujeto se compromete con el medio en una relación creativa y modificadora. El problema central, desde esta vertiente, no es el de una metodología de la prevención, sino el de las estrategias de cambio de la estructura socioeconómica, de la cual el enfermo mental es emergente. El enfermo es portavoz de los conflictos $y$ tensiones de su grupo inmediato, la familia. Pero es también por ello el símbolo y el depositario de los aspectos alienados de su estructura social, portavoz de su inseguridad y su clima de incertidumbre. Curarlo es adjudicarle un rol nuevo, el de agente de cambio, $y$ transformarnos nosotros también en elementos de cambio. (Pichón-Rivière, 1969b).

Consecuente con lo referido respecto a la patología mental, Pichón-Rivière tampoco comprendió lo marginado como el sincretismo de condiciones de vida indeseables surgidas de causas de índole intra-psíquica, sino como símbolo, depositario y portavoz de un contexto socio-económico, político y cultural singular. Pero más aún, toda adaptación activa a la realidad — sea del bajo fondo, sea del enfermo-, no sería mera supervivencia según los recursos propios del sujeto. Sería, antes que nada, vinculación de índole creativa grupal, colectiva y social. 
Al respecto, sus formulaciones se inscriben en un proyecto de estudio más general cuyo hilo conductor es el aprendizaje, donde un sujeto activo construye realidad y se configura así un proceso -y no un estado- que se realiza en contextos socialmente situados (hombre en situación). El aprendizaje "es el proceso de apropiación instrumental de la realidad para modificarla" (Pichón-Rivière, 1995, p. 24), pero para Pichón-Rivière, el sujeto activo está atravesado por relaciones de poder asimétricas, al ser la vida un proceso histórico y socialmente situado donde, de todas maneras, se puede intervenir.

Pichón-Rivière relaciona el aprendizaje a procesos de construcción de conocimiento grupal que se evidencian - en tanto matriz de aprendizaje - en producciones simbólicas que también permiten tramitar la conciencia de saberes (prácticos, preconceptuales y conceptuales). Al hacer explícito lo implícito - al buscar la apropiación instrumental de la creación simbólica grupal que no solo redunda en el desarrollo de capacidades de interpretación de situaciones sociales concretas, sino que también hace a la toma de decisiones respecto a la resolución de problemas-, es posible aprender nuevos aspectos de la realidad concreta y transformarla. Según esta interpretación, el tomar conciencia se relaciona intrínsecamente a hacer explícito lo implícito y esto, a su vez, a la posibilidad de un despliegue de creación del grupo social con miras a la transformación de las estructuras vinculares, sean familiares, institucionales o comunitarias (Pichón-Rivière, 1995).

En este sentido, un sujeto activo construye realidad $y$ dicho proceso tiene lugar en contextos socialmente situados. Se evidencia que la dimensión política es transversal si es comprendida como una acción que efectúa proyecto vital $y$, al hacerlo, transforma las relaciones de poder asimétricas cuando se trata de grupos cuyos derechos son constantemente vulnerados. Desde esta perspectiva es posible preguntarse: ¿en qué contextos se realizan actos creativos?, ¿qué estatuto de sujeto tiene quien crea y respecto de quién o qué?, ¿por qué necesita crear algo nuevo?, ¿cómo hace para crear? Hacer explícito lo implícito refiere a la posibilidad de despliegue de impensados (roles distintos) e impensables (vinculaciones distintas) en un acto creativo que, a medida que transforma, comprende realidades $y$, a medida que comprende, las transforma. Para dar cuenta de estas cuestiones, Pichón-Rivière fundamentó su posición al proponer tres dimensiones de investigación (individuo, grupo e institución o sociedad) y tres tipos de análisis (psicosocial, sociodinámico e institucional), indicando que "no existe una separación neta entre los campos de investigación psicosocial, sociodinámico e institucional: son campos que se van integrando sucesivamente." (PichónRivière, 2008, p. 22).

En relación con lo desarrollado, las formulaciones del autor permiten situar tres cuestiones nodales en relación con este planteo: una dimensión política transversal a la existencia referida en las implicancias de comprender lo singular como inefablemente vincular (¿vinculante?), y esto respecto a lo histórico-social y al ser humano situado; la adaptación activa como proceso creativo; $y$, por último, lo creativo anudado a procesos de aprendizaje que, en tanto despliegan creatividad, habilitan la transformación social. Recuperar estos aportes de Pichón-Rivière permite comenzar a poner de relieve diversas cuestiones respecto a lo que implica vivir en el campo: cómo es que las acciones cotidianas pueden ser mero existir pero, a la vez, pueden crear $y$ desplegar acciones para disputar existencia; cómo ese crear necesita de un aprendizaje entendido en tanto proceso $-y$ no algo que refiere a un punto de partida o de llegada-, y cómo ese aprendizaje refiere a procesos psicosociales situados, es decir, a una construcción del sentido, al implicar su dimensión política. Por último, la creatividad y el aprendizaje suponen procesos de transformación $y$, por tanto, se formularon los siguientes interrogantes: ¿transformación respecto a qué?, ¿qué o quién se transforma? A continuación, se abordará el concepto de subjetivación política con el fin de articular esta referencia. 


\section{PROCESOS DE SUBJETIVACIÓN POLÍTICA}

Se sostiene que los procesos de subjetivación no pueden pensarse siguiendo el modelo de la identificación, ya que no se trata de analizar cómo lo que es se vuelve sí mismo; al contrario, qué y cómo va cambiando eso que cambia, y cómo esa transformación se abre continuamente hacia una indeterminación que no hace posible saber hacia dónde está yendo. Los procesos de subjetivación así entendidos llevan a pensar que se está refiriendo a algo diferente de subjetividad. Dichos procesos no refieren a un sujeto perceptible, identificable; no es posible fijarlos o asignarlos $y$, por tanto, no son fácilmente "situables" (Tassin, 2012). Sin embargo, de ningún modo supone que quien adviene en este proceso no tenga relación "a un tejido familiar, cultural y social que lo ha hecho ser lo que es" (Tassin, 2012, p. 38). Tassin (2012) indica que la subjetivación política refiere a seres "sin obligaciones de fidelidad" a lugares (previa o abstractamente) asignados, al fin, "no soberanos" (ibíd.). Para profundizar en esto se apela a la articulación de los desarrollos de Rivera Cusicanqui (2010) y Achille Mbembé (2011).

Rivera Cusicanqui (2010), con un vocabulario diferente $y$ desde disciplinas distintas (la Sociología y la Historia oral) ha venido analizando en qué medida los procesos de grupos singulares en Bolivia fueron forjando su futuro de acuerdo a una acción sostenida de persistencia vital. Ha puesto empeño en identificar $y$ poner en visibilidad epistemologías distintas que se alojan desde hace siglos en lo que hoy es Bolivia (Rivera y Aillón, 2015). Más específicamente, Cusicanqui detalló los modos en que varones y mujeres que viven en los Andes americanos sostienen un proceso por el cual se ligan a modos de habitar la tierra que - a ojos no habituados - parecen repetirse y repetir lo mismo, pero que, a sus ojos, permite ver la continua novedad de irse transformando precisamente en su insistencia por "estar vivos" (Rivera Cusicanqui,1984). De este modo, con perspectiva disciplinar diferente y con análisis de las experiencias propias en campo, se interpreta que la autora presenta una conceptualización similar a la que se busca forjar: no se trataría de pensar sobre el deber ser de la vida política, sino de comprender cómo los procesos de subjetivación, en situaciones singulares histórico sociales, producen política.

$\mathrm{Su}$ argumento es que esta forma de estar en el mundo apela a aspectos que pueden ser vistos como contradictorios para las epistemologías occidentales, como son: la confluencia en el presente de una memoria de larguísimo plazo (siglos) y de plazo corto (algunas décadas); la posibilidad de alojar en su modo de estar y vivir las contradicciones que se producen por ser aymaras, indígenas, mestizos, algo blancos, algo no-blancos (culturalmente y en las mezclas de biotipos también); $y$ la referencia en tiempo presente a modos de relación con el territorio que son definidos por esas mismas poblaciones (y no por externos o estudiosos de sus acciones) como "campesinos", y referenciados a mecanismos de liberación contra la opresión.

Según los grupos, esto puede tomar distintas formas e, incluso, inmiscuirse en el vocabulario; es decir, en algunos casos se asume un discurso de revolución, mientras que en otros casos el léxico está vinculado a la práctica cotidiana (a la relación con la tierra y la vida diaria, simple y profundamente). Esta casuística boliviana, y la teorización que la autora ha realizado desde la historia oral y la sociología visual, le permite proponer que los procesos de sostenimiento de la vida andina forjan singularidades chíxi, concepto y práctica que se vincula a la "idea aymara de algo que es y no es a la vez, es decir, a la lógica del tercero incluido" (Rivera Cusicanqui, 2010, p. 69). Son modos de estar en el mundo que no pretenden ser unívocos, idénticos a ellos mismos, sino abigarrados $y$, tal vez, confusionales. En este sentido, Rivera Cusicanqui (2010) permite pensar que toda existencia que ha sido atacada y a la que se ha buscado exterminar produce desde la vida respuestas continuas, empecinadas en sostener una presencia erótica (en vez de tanática) en el mundo. Una perspectiva similar presenta Achille Mbembé (2011) cuando escribe:

Tratado como si no existiese más que como simple herramienta e instrumento de producción, el esclavo es, pese a todo, 
capaz de hacer de un objeto, instrumento, lenguaje o gesto, una representación, estilizándolos. Rompiendo con el desarraigo y el puro mundo de las cosas, del cual no es más que un fragmento, el esclavo es capaz de demostrar las capacidades proteicas de la relación humana a través de la música y del cuerpo que otro supuestamente poseía (Mbembé, 2011, p. 26).

En el desarrollo de su argumento, Mbembé (2003) describe y analiza las políticas de muerte que se sostienen en el advenimiento de los Estados nacionales modernos. Su desarrollo conceptual relaciona el Estado moderno con la soberanía, para indicar que "soberanía", en su última expresión, es el poder de decidir quién vive y quién muere, tanto a nivel interno de los territorios nacionales (monopolio de la fuerza estatal) como a nivel de las relaciones entre naciones. Propone pensar que, además, este tipo de política de muerte se desarrolla en el presente con estrategias que dominan los cuerpos desde todos los ángulos posibles, espacialmente: desde el aire (bombardeos, vigilancia desde alturas), desde el suelo, desde el subsuelo y desde el mar. La combinación de esta suerte de ubicuidad del dominio de los cuerpos es lo que -además - genera terror, ya que es imposible comprender de dónde vendrá la violencia y es imposible, por tanto, resguardarse. En ese sentido - y de modo sumamente polémico- invita a pensar que la decisión de quitarse la vida por mano propia, la insistencia en sostener una mirada a futuro como instanciación de la libertad, y la posición de exponerse a salvar a otros, aún con riesgo de vida, son respuestas extremas que exponen la violencia, al igual extrema, de la necropolítica y no deberían pensarse como producto de mentalidades fanáticas o retrógradas.

Mbembé (2003) sostiene también que el poder soberano produce una desterritorialización, una segmentación del espacio y una vigilancia sobre el desplazamiento que desarma todas las redes vitales existentes con anterioridad. Sin embargo, frente a esto, al igual que Rivera Cusicanqui, Membé insiste en la potencia de la vida por parte de quienes deben soportar el ejercicio del terror continuo, e interpreta que si la soberanía se ejerce sobre la política del miedo y en base a la potencia de decidir quién muere, la política de insistencia en la vida se basa en modos combinados $y$, en algunos casos, apelando a formas que él denomina como "marcadas por el exceso" (Mbembé, 2011, p. 65). Por ejemplo, documenta la elección de algunos pueblos de morir antes que vivir esclavizados o atrapados en sus propios territorios, la posición de insistencia en la libertad como un modo de transitar un presente donde habrá un futuro, la presencia de la constancia como una de las formas de la vida. Si bien, su perspectiva dista de ser esperanzadora, lo que permite pensar su ensayo es que existe siempre un plus de insistencia y determinación. Se llama "política" a esa acción posible que podría ser invisibilizada bajo el velo de lo cotidiano. Es una posición desde donde se toma una decisión, inclusive, en momentos donde parece no haber ningún espacio para decidir.

Se denomina entonces "procesos de subjetivación política" a formas de estar en el mundo por las cuales quienes participan de ellas se invisten de una capacidad de transformar $y$ transformarse, $y$, al hacerlo, de convertirse en alguien que antes no eran. Este es uno de los matices que Tassin (2012) distingue específicamente para diferenciar conceptos que parecen parientes entre sí en filosofía política, pero que él insta a diferenciar: sujeto lógico y sujeto físico (la cosa, la materia, el ente, el ser), subjetividad (el ser con conciencia) y sujeción (el ser un sujeto que está sometido). En estos tres conceptos existe una cuestión en común -el principio de identidad - lo que daría a estas formulaciones teóricas la característica de ser sí mismo $(\mathrm{A}=\mathrm{A})$. Distinto de esta formulación, el "proceso de subjetivación" es una propuesta que pretende poner de relieve la constante dinámica del devenir no-sí mismo, un proceso de subjetivación "desidentificatoria" (Tassin, 2012, p. 43) - singularización respecto de una soberanía sobre sí-, es decir, de transformarse.

Al tomar partido frente a otras concepciones teóricas (por ejemplo, la polémica entre Rancière y Althusser, o las conceptualizaciones de Michelle Foucault), Tassin (2012) formula sus conceptualizaciones afirmándose en una 
posición que retoma de Hannah Arendt para subrayar que existen procesos de vinculación, tales que construyen dispositivos de acción colectiva donde se dirimen los efectos de la política; es decir, de la efectuación de vida y de muerte, en última instancia. La distinción en la que pone acento Tassin (2012) es en desarmar cualquier construcción analítica que retome la noción de "sujeto universal" en política para proponer, de forma distinta, que es en el proceso mismo de subjetivación que la singularidad construye (se construye) y va construyendo (dispositivos donde se aloja la acción, que siempre es una acción-entre):

Quizás podríamos en este punto volver al análisis de la acción política propuesto por Arendt, para reconocer en él, contrariamente a lo que afirma Rancière, un modo de subjetivación singular, una singularización o una distinción finalmente librada del mito de la realización universal de la humanidad. (Tassin, 2012, p. 48).

En virtud de lo antes presentado, así como nuestra proposición de que no hay un modo específico de la subjetivación política, sino que esos modos son inmanentes y construidos contextualmente, a continuación se examinará cómo ocurren dichos procesos en las poblaciones rurales con quienes se ha estado trabajando. En cada situación histórica, social, cultural y económica, la pregunta es: ¿cómo es y qué formas toma la subjetivación política?

\section{DE LA POSICIÓN CONCEPTUAL A LA MIRADA ANALÍTICA}

En este apartado se propone ejercitar la mirada analítica tomando la construcción conceptual que se ha venido proponiendo hasta aquí. Antes de realizar el ejercicio analítico se presenta el enfoque metodológico de este trabajo brevemente y el modo en que se generó el material de análisis.

\section{1) CÓMO SE CONSTRUYÓ LA BASE EMPÍRICA DESDE} LA QUE SE REFLEXIONA

El material que se presenta fue generado en las Provincias de Buenos Aires y del Chaco. En el caso de Buenos Aires, la investigación con los Centros Educativos para la Producción Total (СЕРT) comenzó en el año 1991 a partir de un trabajo de asesoramiento solicitado por FACEPT (la Federación que nuclea a los СЕPT) para fortalecer los Consejos de Administración de estos Centros, conformados por las familias de los estudiantes. En el año 2016, se volvió a contactar con los Centros para desarrollar una investigación colaborativa (Heras, 2014) centrada en analizar las formas que adquieren los procesos de tomas de decisiones en las reuniones del Consejo de Administración de estos Centros Educativos, que se realizan cada quince días de forma rotatoria en las casas de los distintos consejeros.

El corpus de datos está conformado por los transcriptos de audio de las 12 reuniones a las que se asistió entre marzo de 2017 y noviembre de 2018. Además, se realizaron entrevistas $y$ conversaciones informales que fueron registradas en el diario de campo a docentes del Centro Educativo, consejeros y otros actores vinculados a la Federación que nuclea a los 35 СЕPT que hay actualmente en la provincia de Buenos Aires. Se ha trabajado con las 11 familias que participan del Consejo de Administración del CEPT, de las cuales 7 de las personas que componen este Consejo tienen como ocupación principal ser "encargados de campo" (Ratier, 2004). En la mayoría de los casos no reciben un ingreso por esta ocupación dada la persistencia de vínculos económicos históricos de explotación que no consideran trabajo a esa labor, sino un servicio sin remuneración - muy ligado a una matriz socio-histórica y cultural de procesos de servidumbre-. A través de acuerdos con el dueño del campo, residen en el predio del cual utilizan una pequeña parte para realizar producciones propias que utilizan para consumo propio $y$, en algunos casos, para la venta. Complementan así su ocupación como encargados con otros trabajos temporarios o 
"changas". En cuanto a las ocupaciones de las 4 familias restantes (algunas de ellas monoparentales) se trata de una portera de una escuela urbana, una empleada municipal, un comisionista/transportista, una ama de casa y una empleada administrativa. La mayoría de los consejeros tienen estudios de nivel primario completos $y$ varios de ellos intentan finalizar sus estudios secundarios con un programa estatal para adultos.

En el caso del Chaco, la investigación comenzó hace 7 años en el marco de una beca doctoral CONICET (2014-2019) con el fin de indagar sobre subjetividad campesina, relaciones de poder y marginación. El corpus de datos para el presente artículo consta de una selección de las 34 entrevistas semi-estructuradas totales realizadas para la investigación, documentos secundarios $y$ datos a partir de la realización de observación participante de la vida de las familias ex-banquineras, tanto en la escuela como en sus casas, como así también parte de los registros de diversos diarios de campo. En este sentido, se ha trabajado con distintos actores del territorio, entre ellos, directivos de la Escuela de la Familia Agrícola "Fortaleza Campesina" (EFA), docentes de la institución, estudiantes, técnicos del INTA articulados al proyecto de la EFA, políticos locales, referentes territoriales, líderes de pueblos originarios (etnia Qom) y familias campesinas — cuyos hijos e hijas asisten a la EFA- particularmente con aquellas familias denominadas "ex-banquineras".

Las "familias ex-banquineras" son un grupo de al menos 100 personas que fueron parte de un proceso de lucha por el acceso a la tierra y otros derechos que inició en el año 1998. Al cabo de 10 años, en 2008, logran - a partir de la articulación mencionada- la apertura de la EFA, como así también la tenencia de hecho de 500 has. expropiadas por el estado provincial, las cuales les permitieron "salir de las banquinas". Esto último se logra, de manera efectiva, en 2009. Previo a este año, las familias vivían entre los alambrados de los campos y los caminos rurales, es decir, en la banquina. De allí su nombre: "Banquineros". Desde el 2008-2009, la EFA pasó a denominarse "la EFA banquinera" y las familias, "ex-banquineras". Las familias que ocupan y ocuparon la banquina están compuestas por, al menos, 3 generaciones, 2 de las cuales han nacido y se han criado en ellas. Por otro lado, las propias familias indican que, a partir del proceso de lucha "ex-banquinero" y la posterior experiencia educativa en la EFA, resignifican su vivencia de banquina con términos como "elección", "apuesta" y "dignidad".

El enfoque metodológico se centra en la etnografía colaborativa de base sociolingüística (Heras, 2014), orientada a producir conocimiento con las familias $y$ docentes de las instituciones educativas, a partir de la identificación de los modos de construcción de sentido que se objetivan en interacciones (Miano, Corro y Heras, 2020) y que se interpretan a partir de convivir en sus territorios y cotidianidad. Como actividades distintivas del enfoque colaborativo en estos contextos específicos se pueden mencionar: instancias para compartir con las familias las interpretaciones que se iban realizando durante el trabajo de campo y la reformulación, en caso de ser necesario, de dichas interpretaciones; escritura conjunta de proyectos; incorporación por parte de las familias $y$ docentes de algunos de los conocimientos generados a partir de la investigación y puesta en uso, ya sea para algunos reclamos y luchas puntuales como así también para orientar tomas de decisiones; difusión del trabajo de estas instituciones y legitimación del sistema de escuelas de alternancia en ámbitos académicos.

En el siguiente apartado, se realiza la interpretación de los procesos de subjetivación política en relación con el marco conceptual metodológico desarrollado líneas anteriores, a partir de identificar en el corpus de datos, significaciones que en perspectiva analítica se distinguen como "series semánticas". Se denomina serie semántica a una vinculación conceptual entre significantes que, al articularse, generan sentido, $y$ en donde el sentido de cada uno de los significantes se produce en relación 
con los otros [sentidos y significantes], de modo tal que el significado de la serie está atravesado por la valencia que cada significante asume en relación a otro de la serie y en relación a otros de las otras series. A su vez, se sostiene que estas series se combinan también de modos complejos entre sí y, en el día a día de las personas con quienes se trabajó, actúan como organizadores de prácticas, discursos y sentidos. A continuación, se desarrolla solo una parte del análisis de estas series semánticas, para dar cuenta de los procesos de subjetivación política $y$ dejar sentadas algunas dimensiones que se retomarán en escritos posteriores.

\section{IDENTIFICACIÓN DE PROCESOS DE SUBJETIVACIÓN POLÍTICA}

\section{1) LA TIERRA: LA DESPOSESIÓN CONTINUA Y EL ARRAIGO}

En el trabajo que se realizó se ha identificado que, si bien los habitantes rurales con quienes se relacionó han formado organizaciones o se han sumado a organizaciones ya existentes, su propia descripción de sí mismos y su posicionamiento efectivo concreto diario, no es enunciado ni de modos totales (en el sentido de auto-adscribirse una pertenencia predominante o única) ni con vocabulario corrientemente asociado a lo que se suele entender como participación política. Al realizar el análisis, se identificaron posicionamientos que se asumen en puntos concretos en el espacio y el tiempo, que pueden leerse como efectuaciones (Deleuze, 2009), en tanto procesos de subjetivación política y se vinculan con el sostenimiento de la vida.

Para comprender los posicionamientos que refieren tanto a reproducir como a defender el deseo de permanecer viviendo en los espacios rurales, resulta necesario, primero, inscribir las acciones colectivas de las familias rurales en un contexto temporal más amplio que recorra algunos aspectos estructurales asociados al modo de producción agrícola hegemónico presente hoy en Argentina. Se hará foco en las diversas formas de acaparamiento de la tierra que se dieron en las dos regiones analizadas a partir de la expansión del cultivo de la soja desde mediados de la década de 1990, ya que se considera que el acceso a la tierra es un factor de peso en cuanto a las posibilidades de permanecer viviendo en el campo. Angus $(2013 ; 2014)$ ha tomado la noción de desposesión continua, inspirado en el trabajo pionero de Rosa Luxemburgo (1913) para referirse a este tipo de situaciones donde la rapiña de la acumulación continua opera a la vez como modo económico de organizar las relaciones sociales y como modo cultural, ético, estético y político, simultáneamente. Es en todos estos aspectos que las experiencias que se analizan aquí, junto a sus participantes, cobran un relieve significativo.

Desde mediados de la década de 2000 se registra un proceso conocido como "acaparamiento global de tierras" (Gras, 2017) que implica que largas extensiones de tierra pasan a manos de grandes actores para ser destinadas a la producción de un grupo reducido de commodities (¿materia prima?), entre ellos, la soja. Estos actores son principalmente mega empresas que concentran la producción de soja y maíz en el país, $y$ que también ocupan posiciones importantes en otros tipos de producciones (ganadera, leche $y$ arroz). Siguiendo a Gras (2017), en la provincia de Buenos Aires, el acaparamiento de tierras se dio principalmente a través del arrendamiento, tanto de grandes extensiones como también de medianas $y$ pequeñas. Esto implica que varios actores locales, identificados como grandes propietarios, siguen teniendo peso y presencia junto a los actores globales. Este hecho incide en los vínculos sociales locales $y$ en las posibilidades de que se den procesos de subjetivación política en las familias rurales con las cuales se trabajaron, quienes no son propietarias de tierras, pero tienen muchas veces vínculos laborales con esos grandes propietarios.

A mediados de 1990, los productores pampeanos, debido al aumento del precio de la tierra en esta región, buscaron campos en las regiones extra-pampeanas extendiendo la frontera agraria hacia el norte. Este proceso implicó, por ejemplo, que entre 1997 y 2010, la superficie sojera aumente un $443 \%$ en la provincia de Chaco, de acuerdo con datos aportados por Gras (2017). Para esta región del 
Gran Chaco, el desmonte de bosques nativos, así como, el despojo y el arrinconamiento de poblaciones campesinas e indígenas fue un factor de peso en las formas de acaparamiento de la tierra.

Mientras que, en la región pampeana, la producción sojera se mantiene o aumenta levemente desde 2010, en la región del Gran Chaco comienza a disminuir como consecuencia de la caída del precio de la soja y el aumento de costos (principalmente del transporte). Como consecuencia del menor rendimiento - en términos relativos - de la tierra de esta región y la región pampeana, su producción se volvió menos rentable, lo cual acarrea la retirada de varios pools de siembra en la zona y comienza a bajar el valor de las tierras.

Como se puede observar en este breve recorrido, ambas regiones se caracterizan por la concentración de la tierra ligado a un proceso de acaparamiento por parte de actores con peso económico y político, tanto locales como transnacionales. Este escenario advierte, entonces, acerca de dos aspectos importantes a los fines de comprender la acción política rural hoy. Pone de relieve la necesidad de comprender nuestras acciones contemporáneas en una historia de mediano plazo al menos, donde se pueda hacer visible que han existido marcos culturales, económicos, políticos y éticos en el pasado más o menos reciente que han ejercido una fuerte tiranía sobre algunos grupos. Sin embargo, también pone de relieve, tal vez cruelmente, que las acciones de defensa de la vida están en relación con una amenaza de muerte cotidiana. Esa amenaza es mucho más que una amenaza coyuntural: es una (necro) política. Por tanto, un aspecto importante a destacar en este panorama es que muchos de estos grupos sostienen su ser político (su estar en el mundo, tomar decisiones, albergar una forma de ser $y$ hacer) a partir de lisa y llanamente reproducir sus vidas, lo que en este marco también, a la vez, se puede referenciar como defender la vida, o, más concretamente, defender sus vidas.

Estas dinámicas informan acerca de las luchas colectivas emprendidas hoy por las familias rurales, las tensiones y los actores a los que se enfrentan, así como, las posibilidades de crear y recrear formas de permanecer, trabajar $y$ vincularse con la tierra. Asimismo, las luchas colectivas ponen en conocimiento de procesos de coalición que suponen instancias de transformación donde intervienen procesos de subjetivación política.

Se detallan ahora ciertas significaciones específicas surgidas a partir de los trabajos propios en territorio que refieren a una construcción de subjetividad auto-definida como habitantes del medio rural, $y$ una posición social-política ligada a la defensa de una forma de vida vinculada a lo rural en los términos en que estos habitantes desean definirla. Así, a la vez que existen efectuaciones que pueden entenderse como formas de vida que se reproducen $y$, a la vez, resisten a ser arrasadas, también pueden ser entendidas como, en sí mismas, una forma singular de vivir políticamente.

\section{2) LAS COALICIONES: ESCUELAS DE ALTERNANCIA Y HABITANTES RURALES}

En el caso del Chaco, la pregunta que permite explicitar el vínculo entre la acción política y la vida es, entre otras, la siguiente: ¿cómo fue posible la EFA? Al respecto, la coalición entre diversos actores del territorio no solo ha sido compleja por la cantidad de actores que se fueron articulando, sino además por las características de uno de estos actores: un sujeto completamente marginado en la escena local: "los banquineros". En este sentido, ¿por qué los habitantes rurales que antes vivían en las banquinas dirán que los docentes que querían abrir una EFA "encajaron" en su entendimiento [como campesinos] dando lugar a la posibilidad de ir uniéndose?

Sobre esto se pueden colegir ciertos sentidos por parte de los ahora "ex-banquineros" que, mirando retrospectivamente su situación de banquina a partir de su articulación a la EFA, refieren que su proceso de lucha - de al menos diez años de duración - ha sido una "apuesta, una elección" (D.R., comunicación personal, octubre de 2018), que ha tenido como eje transversal la "dignidad": la de no migrar a centros urbanos, como así también la de elegir la banquina para seguir viviendo. Elegir la banquina 
no pareciera referir a una elección entre una posibilidad $u$ otra, sino a elegir entre su forma de vida o su pérdida: "De irnos ¿dónde íbamos a plantar para comer? No podíamos tener animalitos, no se puede tener nada" (D. R., comunicación personal, octubre de 2018).

Aquí, plantar para comer no haría referencia a una incapacidad de aprender otras prácticas para vivir en las urbes, sino a que su forma de ser en el mundo está constitutivamente ligada a la tierra, aún en la urbe, la referencia sigue siendo su forma de vida. Ser campesino no es un oficio, es una cosmología (Villareal, 2013). Elegir es seguir eligiendo "ser campesinos" [aún] "sin tierras". De aquí su carácter intrínsecamente político. A su vez, se indica en territorio que una de las preguntas que insistía en el grupo banquinero parte de la lucha fue ¿Tierras sin educación, para qué? (registro de campo, marzo de 2015). En este sentido, una de las referentes banquineras diría que siempre quiso que sus hijos pudieran educarse para poder salir de donde estaban - las banquinas - y "ser alguien" (F. B., comunicación personal, octubre de 2017). Lo interesante es que ese ser alguien se refiere más a dejar de sentirse "ciudadanos ni de cuarta" (Foro Multisecotrial por la Tierra, Documento Audiovisual, 2010) que a una autopercepción de sujeto del arrasamiento (Carballeda, 2008). A su vez, los docentes que querían abrir una EFA en el lugar se preguntarían "Educación sin tierras, ¿cómo?" (registro de campo, septiembre de 2016). En este sentido: ¿cómo llevar adelante un proyecto educativo que se asienta en principios que propenden a la autonomía, arraigo $y$ desarrollo campesino sin tener tierras?

Se erige así una necesidad en común - tierras - y una articulación de sentidos común - tierras/educación-, motivada por cuestiones distintas. Esta necesidad común (Montero, 1994) no fue el elemento nodal sobre el que se erigiría el proceso de organización comunitario; necesitó de una trama compleja de sentidos que se articularan entre uno y otros para "ir encajando" mutuamente, comenzando un derrotero de coaliciones $y$ disputas que culminaría con la apertura de la EFA en 2008 y con la obtención de tierras para el grupo ex-banquinero en 2009.

Por último, los sentidos de "ser alguien", no seguir siendo "ciudadanos, ni de cuarta", y llevar adelante un proyecto centrado en el arraigo, refieren a una dimensión de reconocimiento de singularidades que se encuentran desentramadas, marginadas del todo social. Es decir, el reconocimiento en tanto disputa de ciudadanía.

En el caso de las familias de la provincia de Buenos Aires, ser habitantes del medio rural es una elección a la cual se aferran a pesar de varias situaciones complejas que tienen que enfrentar por esa elección. En el trabajo de campo, se ha documentado que permanecer en el medio rural para estas familias implica enfrentarse a inundaciones, incendios, fumigaciones con agrotóxicos, la rudeza del trabajo con la tierra - lo cual genera afecciones a la salud en varios de ellos a edades tempranas-, falta de trabajo, el desarraigo de seres queridos, escasez de servicios básicos entre los cuales se destaca el estado de los caminos que transitan. En relación con este último aspecto, una de las consejeras mencionó: "yo no me voy a ir a vivir a la ciudad porque ellos no me arreglan el camino" (K. O., comunicación personal, diciembre de 2016). El campo se construye como una elección opuesta a la ciudad, por lo que implica como modo de vida, en el cual, el vínculo con la naturaleza y principalmente con la tierra, se constituye como sustento para la vida.

Esta vinculación entre tierra $y$ vida es tal que varios de ellos no pueden imaginarse viviendo en otro lugar. Se ha documentado la situación de una familia en la cual el propietario del campo para el cual trabajaban y en el cual residen había decidido vender el predio. El padre de esta familia, al ser consultado por los docentes de la escuela respecto a su destino respondió: "pero si yo estoy ahí" (Transcripto reunión del Consejo de Administración, mayo de 2017), como si la única posibilidad de vida fuese en ese lugar. De hecho, el campo se vendió y los propietarios cambiaron, pero esa familia "sigue ahí" o, como explicó la directora de la escuela: "vendieron el campo con ellos (la familia) adentro" (registro de campo, noviembre de 2019). 
Las familias perciben que el Estado se ha olvidado de ellos, que son una población invisibilizada $y$ que frente a ese olvido es necesario unirse con otros "porque juntos podemos más" (K. O., comunicación personal, diciembre de 2016). Frente a esta situación de invisibilización, las personas reclaman reconocimiento ("queremos que nos reconozcan"), su existencia como habitantes del medio rural.

3) LA FORMA SINGULAR DE VIVIR POLÍTICAMENTE: SERIES SEMÁNTICAS Y ACCIÓN POLÍTICA

De esta manera, a partir de ambas experiencias, se identificaron series semánticas que permiten visualizar e ir entramando diversas cuestiones a la vez: 1. la insistencia por reproducir sus formas de vida; 2 . la disputa por el reconocimiento; 3 . el despliegue de sus singularidades; 4 . las coaliciones y 5 . las disputas entre una política de la muerte (necropolítica) y de la vida (reproducción socio-cultural).

Las series semánticas identificadas pueden sintetizarse en la unión de los siguientes términos: [tierra/trabajo/vida]; [arraigo/ territorio/escuela]; [ambiente saludable/derechos/lucha]. En términos generales, a partir de los datos presentados, en particular, la cadena semántica tierra/trabajo/vida se constituye como una forma de vida arraigada a la tierra, vista no como algo a poseer o acaparar, sino como posibilidad para proyectar la vida. Esta, a su vez, está articulada con lo educativo, a partir tanto de la necesidad de reconocimiento: "Teníamos que aprovechar, era la primera vez que algo era hecho para nosotros" (F. B., comunicación personal, octubre de 2017); como también de saldar una vulneración y, a través de la institución educativa, gestionar otros derechos vulnerados. Esto se liga con poder seguir reproduciendo sus formas de vida en el campo, no tener que migrar la familia entera y perder sus formas de reproducción económica (consumo de lo que se produce $y$ venta de excedentes) o cultural (transmisión de una generación a otra de lo que significa pertenecer a la tierra). A su vez, los proyectos educativos asientan sus bases ético-políticas y político-pedagógicas en propuestas que detentan como eje transversal el arraigo $y$ desarrollo campesino, vistos no como algo a separar de la existencia de los habitantes rurales, sino como posibilidad para proyectar un aprendizaje situado; es decir, articulada con la forma de vida de los habitantes rurales.

Las series semánticas permiten visualizar una compleja trama de dimensiones plegadas (Fernández, 2007): algo que existe, entonces insiste (forma de vida arraigada); algo que resiste, entonces disputa (marco de desposesión continua); $y$ algo que excede, entonces crea (arraigo como forma de vida). Esto se des-pliega (Zibechi, 2005; Fernández, 2006) sin conformarse un sujeto político a priori o a posteriori, sino mediante singularización (Tassin, 2012), presentándose así toda su dimensión política.

La elección de permanencia en el medio rural por parte de estas familias es - de acuerdo a este análisis - un proceso continuo de acciones políticas. Esa elección es, a la vez, tanto una apuesta por sus formas de existencia como también una intervención en sus condiciones de vida que se erige en tensión y resistencia a la desposesión continua.

Por último, las series semánticas habilitan articular la vida cotidiana, las acciones políticas, los agenciamientos y los procesos de subjetivación política. Al igual que respecto al poder (Foucault, 1986), interesa menos definir el qué (qué es la subjetivación política) que el dónde (dónde situarla) y el cómo (cómo se despliega).

Los habitantes rurales con los que se han trabajado, retomando la conceptualización de subjetivación política, no comienzan a ser alguien distinto en un momento determinado -ni a priori, ni a posteriori-. Los habitantes rurales no se configuran como algo que ahora son que antes no eran, sino al revés: ahora dejaron de ser algo que antes era del orden de lo situable. En este punto, la articulación entre subjetivación política y singularización (Tassin, 2012) no solo permite problematizar la dicotomía sujeto revolucionario-sujeto arrasado, sino, sobre todo, permite comprender que es en el despliegue de una singularidad - en parte atestiguada en la forma en que van integrándose sentidos en las series semánticas- en dónde se puede ubicar y comprender cómo se produce la 
subjetivación política. A su vez, este despliegue adquiere sentido en la vinculación, es decir, refiere a otros - sea a las EFA para su concreción, sea al marco de la necropolítica para su disputa, sea a la política para su reconocimiento de una forma de vida singular-. Así, actos de la vida cotidiana evidencian su peso político como acciones $y$ se visibilizan en tanto acciones que aparecían veladas. Finalmente, emergen como formas singulares de vivir políticamente.

\section{DISCUSIÓN Y CONCLUSIONES}

A lo largo del escrito se ha señalado cómo, al insistir por una forma de vida singular, los pobladores rurales con quienes se trabajaron producen una interpelación de los marcos jurídico-políticos y socio-económicos en que se encuentran situados con su mero hacer. De este modo, $y$ como punto de partida, se ha conceptualizado al proceso de efectuación vital, decidido a sortear la encrucijada vida-muerte en la que algunas poblaciones son ubicadas por otros, como un proceso de subjetivación política, lo cual, a la vez, refiere a la des-identificación y a la transformación, sin por ello ponerse en entredicho la propia singularidad. Singularidad que se despliega $y$, a la vez, que nada descubre de sí para sí misma, sino en tanto vinculación respecto a otros.

En este sentido, en términos de la psicología social Pichoniana, se identificaron procesos de aprendizaje ligados a la creatividad y a la transformación, donde se evidencia una relación (consciente o no, más o menos explicitada o no) entre posición vital cotidiana e interpelación de las estructuras existentes. Las coaliciones no tienen su valor creativo y transformador solo referido a la coalición en sí misma — la articulación en sí-, sino en el cómo de esta. En las coaliciones, para que sucedan, hay algo que no se cede, hay un límite y una reproducción: la propia forma de vida singular de los habitantes rurales. Es decir, del arraigo a las coaliciones. Y esto, es solo en la vinculación que adquiere su posibilidad de despliegue y su potencia transformadora. A su vez, necesita de - y ha permitido - una ubicuidad diferente, otra, inesperada, para un marco que no cesa en su avance de desposesión. No se descubre algo nuevo de sí —era obvia la banquina para las personas campesinas como espacio a ser habitado, como era obvio para la familia que, por más que se vendiera el campo, allí se quedarían, sea quien fuere su propietario legal-; se despliegan tanto las potencialidades y problemas de la vinculación, como la posibilidad misma de experimentarla. Así, toda supuesta adaptación de estos habitantes rurales es más un acto creativo de transformación con otros y respecto de otros que un hecho de supervivencia. Un proceso que permite la emergencia de una subjetividad in-situable a partir del despliegue de la singularidad de un sujeto situado, en toda su dimensión política.

Este marco analítico ha permitido identificar que los pobladores rurales, en su existencia cotidiana - es decir, en la propia efectuación de sus vidas-generan elecciones, decisiones, acciones y coaliciones comunitarias consecuentes con la insistencia de una forma de vida, que, a la vez, pone en tensión la política de arrasamiento de lo que se identificó como "necropolítica". En este punto, los marcos conceptuales de Pichón-Rivière, Mbembé y Cusicanqui, coinciden en señalar una potencia de la acción situada ahí para enfrentar la segmentación, la desposesión, el empuje al desarraigo producto de la acumulación y la explotación. Sin embargo, tal vez las conclusiones que estos autores sacan son distintas entre sí, o las disciplinas de origen hacen posar sus miradas en aspectos distintos. Para Pichón-Rivière es el aprendizaje y la creación social; para Mbembé es el poder de decidir qué hacer con la vida, al punto de poder ejercer la muerte antes que resignarse a una vida sin vida; para Cusicanqui es la mirada posada sobre el tiempo (pasado largo, pasado inmediato, pasado en el presente continuo, futuro, futuro empujando desde atrás). Es decir, allí donde pareciera no haber forma alguna de posibilidad, existe autonomía.

Al desplegarse la potencia de la singularización como acción situada, se transforman a sí mismos y a su entorno, por lo tanto, construyen realidades. Es por esto que, aunque sean acciones de la vida cotidiana, se afirma 
que son procesos de subjetivación política en tanto generan transformaciones que permiten crear lo impensable: proyectar la vida en tierras consideradas marginales (banquina o lote de tierra del cual no son dueños); abrir escuelas acordes a esos proyectos de vida; juntarse con otros para tomar decisiones. A su vez, en esa creación de lo impensable, la posibilidad de que, al producir otras condiciones de existencia, no se produzcan cortes de sentido ni de práctica con otras condiciones anteriores. Estas se transforman, inclusive conservando en sí mismas aspectos que a miradas exteriores $y$ desinformadas podrían parecer contradictorias $o$ incoherentes (como mantener el modo banquinero luego de "salir" de la banquina; mantener un arraigo a la tierra tal que el obcecado movimiento de precisamente no moverse pueda ser entendido por otros como que son tratados como "cosas que se venden con el terreno").

La posición analítica en este artículo permite distinguir estos otros matices posibles: no se trata de la ausencia total del sujeto campesino para la construcción política, como tampoco de un sujeto políticamente acrítico y pasivo, ni de una subjetividad donde existe un antes/un después cuya frontera está trazada por la capacidad o no de configurarse como organización. Se propone una forma de problematización y elaboración que toma en cuenta como núcleo central la posibilidad de visibilizar efectuaciones que contrarrestan la necropolítica.

También, este marco analítico permite identificar cómo las personas producen transformaciones de sí mismas y del entorno mediante procesos de aprendizaje que se sostienen y recrean en la construcción de coaliciones cimentadas en la apuesta por la efectuación de la vida en sus propios términos. Dichas efectuaciones, desde esta perspectiva, son entendidas como procesos complejos de subjetivación política. Efectuaciones que a la vez insisten (forma de vida singular), resisten (disputan entre una política de vida y muerte) y transforman (desidentificación/singularización, aprendizaje y creatividad en coaliciones). Así, las coaliciones no podrían darse ni entenderse por fuera de la compleja trama de relaciones de sentido que se han denominado series semánticas. Se trata de articulaciones de sentidos y significantes que, mediadas por procesos de des-identificación, creatividad, aprendizaje y transformación, permiten el despliegue de la singularización respecto de otros, $y$, por tanto, incesantemente le disputan vida a toda política de muerte.

Al respecto de la subjetivación política: si no siempre donde existe poder, hay resistencia; entonces, donde sí la hay tal vez la pregunta a contestar sea ¿cómo fue posible? Y si siempre donde existe poder hay resistencia (Foucault, 1986), donde no pareciera haber, tal vez la pregunta a contestar sea ¿cómo podrían ser otras formas de hacer política que no estamos pudiendo ver?

\section{REFERENCIAS}

Amin, S. (2010). El capitalismo hoy en día. Cuadernos del Cendes, 27(74), 141-157. http://ve.scielo.org/scielo.php?script=sci_ arttext\&pid=S1012-25082010000200007

Angus, I. (2013). The Undiscovered Country: Essays in Canadian Intellectual Culture. Athabasca University Press.

Angus, I. (2014). Continuing Dispossession: Clearances as Literary and Philosophical Themes. Contours, 4. https://www.sfu.ca/ humanities-institute/contours/issue4.html

Becerra, G. (2015). Enrique Pichón-Rivière: los orígenes de la psicología social. Revista Latinoamericana de Metodología de las Ciencias Sociales (RELMECS), 5 (1), 1-13.

Bengoa, J. (2003). 25 años de estudios rurales. Sociologías, 10, 36-98.

Cáceres D. M., (2014). Amenazas y desafíos que enfrenta el campesinado en Argentina. ¿Descampesinización o Persistencia? En C. Craviotti (Ed.), Agricultura Familiar en Latinoamérica. Continuidades, Transformaciones y Controversias (pp 205-232). Editorial Ciccus.

Carballeda, A. J. M. (2008). Los cuerpos fragmentados: la intervención en lo social en los escenarios de la exclusión y el desencanto. Paidós.

Conti, S. (2017). Psicología, Organizaciones Rurales y Modelos de Desarrollo: experiencias recientes de la zona 
andina y la línea sur rionegrinas [Tesis de Doctorado]. Facultad de Psicología. Universidad de Buenos Aires.

Deleuze, G. (2009). Diferencia y repetición. Amorrortu Editores. [ $1^{\text {a }}$ ed. francesa Presses Universitaires de France, 1968].

Fabris, F. A. (comp.) (2014). Pichón-Rivière como autor latinoamericano. Lugar Editorial.

Fernández, A. M. (2006). Politica y subjetividad: asambleas barriales y fábricas recuperadas. Tinta Limón.

Fernández, A. M. (2007). Lógicas colectivas, subjetividad y política. En Y. Franco, H. Freire y M. Loreti (Comps.), Insignificancia y autonomía. Debates a partir de Cornelius Castoriadis (pp. 45-50). Biblos.

Foro Multisectorial por La Tierra (2010). Banquineros. Los Sin Tierra. [Archivo de Vídeo]. Youtube. https://www.youtube. $\mathrm{com} /$ watch? $v=\mathrm{kxeLB} 2 \mathrm{AcXxk} \& \mathrm{t}=615 \mathrm{~s}$

Foucault, M. (1986). Defender la sociedad. Fondo de Cultura Económica.

Gras, C. (2017). Expansión sojera y acaparamiento de tierras en Argentina. Desarrollo Económico, 57(221), 149-163.

Heras Monner Sans A.I. (2014). Lógica colaborativa y generación de conocimiento colectivo. Alcances y tensiones en las relaciones investigación-sociedad. Población \& Sociedad, 21(2), 137-150.

Landini, F. P. (2009). Psicología en el ámbito rural: subjetividad campesina y estrategias de desarrollo. [Tesis Doctoral]. Facultad de Psicología. Universidad de Buenos Aires.

Luxemburgo, R. (1913). La acumulación de capital. Edicions Internacionals Sedov.

Martín-Baró, I. (1986). Hacia una psicología de la liberación. UCA.

Marx, K. (1852). The Eighteenth Brumaire of Louis Bonaparte. Die Revolution.

Mbembé, A. (2003). Necropolitics. Public Culture, 15(1), 11-40. Traducción por Libby Meintjes.

Mbembé, A. (2011). Necropolítica. Editorial Melusina. Traducción de Elisabeth Falomir Archambault.
Miano, M. A., Corro, E. S. L. y Heras, A. I. (2020). Escuelas rurales de alternancia y cogestión. Un análisis sociolingüístico $y$ etnográfico de las tomas de decisiones en el Consejo de Administración. Revista Brasileira de Linguística Aplicada, 20(3), 655-692. https://doi.org/10.1590/19846398202016456

Montero, M. (1994). Psicología social comunitaria. Teoría, método y experiencia. Paidós.

Pichón-Rivière, E. (1969a). Estructura de una escuela destinada a la formación de psicólogos sociales. El proceso grupal. Del psicoanálisis a la psicología social (pp. 149-160).

Pichón-Rivière, E. (1969b).Una teoría del abordaje de la prevención en el ámbito del grupo familiar. El proceso grupal. Del psicoanálisis a la psicología social (pp. 185-190).

Pichón-Rivière, E. (1995). Diccionario de términos y conceptos de psicología y psicología social. Nueva Visión.

Pichón-Rivière, E. (2008). Teoría del vínculo. $26^{a}$ reimpresión. Nueva Visión.

Quiroga, A. (1985). Revisión histórica: E. Pichón-Rivière. En María Cunha Gayoto (coord.), Seminario (pp. 13-31).

Ratier, H. (2004). Sobrevivir sin tierra: estrategias para reproducirse y crecer entre encargados de campo y empleados rurales. VII Congreso Argentino de Antropología Social, Córdoba, Argentina, 26 de mayo de 2014.

Rivera Cusicanqui, S. (1984). Oprimidos pero no vencidos. Luchas del campesinado aymara y qhechwa, 1900-1980. HISBOL CSUTCB.

Rivera Cusicanqui, S. y Aillón Soria, V. (2015). Antología del pensamiento crítico boliviano contemporáneo. ClACSO.

Rivera Cusicanqui, S. (2010). Ch'ixinakax utxiwa. Una reflexión sobre prácticas y discursos descolonizadores. Tinta Limón Ediciones.

Tassin, E. (2012). De la subjetivación política. Althusser/Rancière/ Foucault/Arendt/ Deleuze. Revista de Estudios Sociales, 43, 36-49. 
Thomas, W. I y Znaniecki, F. (1918). El campesino polaco en Europa y América. Universidad de Chicago.

Villareal, P. M. (2013). Una crítica al multiculturalismo a partir de la Antropología Simétrica: otro abordaje para la cuestión de la diversidad. VII Jornadas de Jóvenes Investigadores. Instituto de Investigaciones Gino
Germani-Facultad de Sociología, Universidad de Buenos Aires.

Zibechi, R. (2005). Dispersar el poder. Los movimientos como poderes antiestatales. Tinta Limón.

Fecha de ingreso: $18 / 08 / 2020$ Fecha de aprobación: 05/10/2021 
